\title{
HUBUNGAN ANTARA BERMAIN MENGENAL WARNA DENGAN PERKEMBANGAN KOGNITIF ANAK DI TK FRATER BAKTI LUHUR MAKASSAR
}

\author{
Ufra Musyahidah $^{1}$, Sriwahyuni $^{2}$, Darwis $^{3}$ \\ ${ }^{1}$ STIKES Nani Hasanuddin Makassar \\ ${ }^{2}$ STIKES Nani Hasanuddin Makassar \\ ${ }^{3}$ STIKES Nani Hasanuddin Makassar
}

(Alamat Korespondensi : uframusyahidah081297@gmail.com/082343943968)

\begin{abstract}
ABSTRAK
Usia dini merupakan kesempatan emas bagi anak untuk belajar, sehingga disebut usia emas (golden age) yang perlu dioptimalkan karena anak berkembang dari berbagai aspek. Menurut WHO, 2016 mengungkapkan bahwa 250 juta, atau 43\%, anak-anak di negara berpenghasilan rendah dan menengah tidak mengalami perkembangan penuh. Salah satu cara meningkatkan kognotif anak dengan cara bermain mengenal warna. Kemampuan mengenal warna berkaitan dengan perkembangan kognitif, yang dapat mengembangkan kemampuan otak anak untuk berpikir. Tujuan penelitian adalah untuk mengetahui hubungan antara bermain mengenal warna dengan perkembangan kognitif anak di TK Frater Bakti Luhur Makassar. Penelitian ini menggunakan metode penelitian deskriptif analitik dengan rancangan cross sectional study. Pengambilan sampel menggunakan systematic random sampling dengan jumlah sampel sebanyak 48 anak. Pengumpulan data menggunakan kuesioner dan dianalisa menggunakan chi-square. Hasil penelitian ini menunjukkan bahwa responden yang baik dalam bermain mengenal warna berjumlah 34 responden, dimana terdapat 32 responden $(94,1 \%)$ yang mengalami perkembangan kognitif dan 2 responden $(5,9 \%)$ yang tidak mengalami perkembangan kognitif. Sedangkan responden yang kurang dalam bermain mengenal warna berjumlah 14 responden, dimana terdapat 9 responden $(64,3 \%)$ yang mengalami perkembangan kognitif dan 5 responden $(35,7 \%)$ yang tidak mengalami perkembangan kognitif dengan $p=0,017$. Kesimpulan dalam penelitian ini adalah ada hubungan antara bermain mengenal warna dengan perkembangan kognitif anak di TK Frater Bakti Luhur Makassar.
\end{abstract}

Kata Kunci : Anak, Bermain Mengenal Warna, Perkembangan Kognitif.

\section{PENDAHULUAN}

Usia dini merupakan kesempatan emas bagi anak untuk belajar, sehingga disebut usia emas (golden age) yang perlu dioptimalkan karena anak berkembang dari berbagai aspek yaitu aspek fisik, aspek kognitif, aspek sosial dan emosional (Khaironi, 2018).

Berdasarkan data dari World Health Organization (WHO), 2016 mengungkapkan bahwa 250 juta, atau 43\%, anak-anak di negara berpenghasilan rendah dan menengah tidak mengalami perkembangan penuh mereka. Perkembangan anak usia dini meliputi perkembangan fisik, sosio emosional, kognitif dan motorik, terjadi pada anak usia 0-8 tahun. Bukti terbaru yang menyebabkan tingginya beban anak-anak yang berisiko mengalami perkembangan yang tidak optimal karena intervensi yang tidak efektif, fasilitas kesehatan, dan penghasilan (WHO, 2018).

Data dari Riset Kesehatan Dasar, 2018, menunjukkan total indeks perkembangan anak pada anak usia 36-59 bulan di Indonesia yaitu $88,3 \%$, dimana $64,6 \%$ mengalami perkembangan kognitif, $97,8 \%$ mengalami perkembangan fisik, $69,9 \%$ mengalami perkembangan sosial emosional dan 95,2\% mengalami perkembangan kemampuan berbicara dan berbahasa (Kemenkes RI, 2018).

Batasan tentang anak usia dini antara lain disampaikan oleh NAEYC (National Association for The Education of Young Children) yang mengatakan bahwa anak usia dini adalah anak yang berada pada rentang usia 0-8 tahun, yang tercakup dalam program pendidikan di taman penitipan anak, penitipan anak pada keluarga (family child care home), pendidikan prasekolah baik swasta maupun negeri, Taman Kanak-Kanak, dan Sekolah Dasar (Vanagosi, 2015).

Menurut Undang-undang Republik Indonesia Nomor 20 tahun 2003 tentang Sistem Pendidikan Nasional pada Pasal 1 ayat 14 menyatakan bahwa pendidikan anak usia dini adalah suatu upaya pembinaan yang ditujukan kepada anak sejak lahir sampai dengan usia enam tahun yang dilakukan melalui pemberian rangsangan pendidikan untuk membantu pertumbuhan dan 
perkembangan jasmani dan rohani agar anak memiliki kesiapan dalam memasuki pendidikan lebih lanjut. Pendataan Depdiknas pada tahun 2002, baru $28 \%$ dari 26,1 juta anak usia 6 tahun yang mendapat pendidikan usia dini. Sebagian besar di antara mereka, yakni 2,6 juta, mendapatkan pendidikan dengan jalan masuk ke Sekolah Dasar pada usia lebih (Wulandari, dkk., 2016).

Kemampuan mengenal warna berkaitan dengan perkembangan kognitif, yang dapat mengembangkan kemampuan otak anak untuk berpikir (Kasmini \& Purba, 2016). Warna juga dapat memancing kepekaan terhadap penglihatan yang terjadi karena warna yang ada pada benda terkena sinar matahari baik secara langsung atau tidak langsung yang kemudian dapat dilihat oleh mata. Menurut Susanto (2002:113) dikutip dalam Muliani (2017), mengenalkan warna sejak usia sangat dianjurkan agar anak dapat membedakan dan mengetahui macam-macam warna dasar dan komplemennya. Warna-warna yang dapat dikenalkan pada anak yaitu warna primer (merah, kuning, dan biru) lalu pada warna sekunder (hijau, ungu, dan jingga), dan pada warna netral (cokelat) hingga warna putih dan hitam.

Menurut Sumanto (2005) dalam Hernia (2013), kreatifitas kegiatan seni rupa antara lain melukis atau menggambar, mewarnai, mencetak, melipat, menganyam, dan membentuk. Namun dalam kegiatan seni rupa yang paling efektif digunakan dalam pengenalan warna adalah melukis/menggambar, mewarnai, melipat, meronce, dan mencetak atau mengecap.

Berdasarkan data dari TK Frater Bakti Luhur Makassar, menunjukkan bahwa jumlah siswa di TK Frater Bakti Luhur Makassar pada tahun 2018 jumlah siswa di TK Frater Bakti Luhur Makassar sebanyak 92 siswa, dimana terdapat 44 siswa yang berjenis kelamin lakilaki dan 48 siswa yang berjenis kelamin perempuan, sedangkan jumlah siswa usia 5-6 tahun sebanyak 36 siswa. (Tata Usaha TK Frater Bakti Luhur Makassar, 2018). Berasarkan hasil wawancara sederhana dengan guru di TK Frater Bakti Luhur Makassar, didapatkan bahwa anak terkadang belum mengerti semua warna yang diberikan dan sering kali menukar warna-warna kubus yang diberikan serta masih ada anak di TK Frater Bakti Luhur Makassar yang tingkat perkembangan kognitif anak terbilang lambat, hal dikarenakan struktur sosial masyarakat bertingkat seperti perekonomian dan pola asuh responden tua.

\section{BAHAN DAN METODE}

Lokasi, Populasi Dan Sampel

Penelitian ini dilaksanakan di Taman Kanak-Kanak Frater Bakti Luhur Kota Makassar pada tanggal 15 - 20 Juli 2019. Populasi dalam penelitian ini adalah semua anak usia 4-6 tahun di TK Frater Bakti Luhur Makassar sebanyak 92 anak dengan jumlah sampel sebanyak 48 anak.

\section{Pengumpulan Data}

1. Data primer

Pengumpulan data primer diperoleh dengan menggunakan kuesioner yang telah disediakan.

2. Data sekunder

Pengumpulan data sekunder diperoleh dari tata usaha di TK Frater Bakti Luhur Makassar.

\section{Pengolahan data}

1 Editing

Proses editing dilakukan setelah data terkumpul dan dilakukan dengan memeriksa kelengkapan data, memeriksa kesinambungan data, dan memeriksa keseragaman data.

2 Koding

Memberikan angka pada setiap alternatif jawaban, dimana alternative jawaban yang diberikan.

3 Processing

Setelah semua isian observasi terisi penuh dan benar dan juga sudah melewati perkodingan

\section{Analisa Data}

1. Analisis Univariat

Analisa univariat bertujuan untuk mendeskripsikan karakteristik setiap variabel penelitian. Bentuk jenis analisis univariat tergantung dari jenis datanya.

2. Analisis Bivariat

Analisis bivariat yang dilakukan terhadap dua variabel yang diduga berhubungan atau berkorelasi (Notoatmodjo, Metodologi Penelitian Kesehatan, 2014).

\section{HASIL PENELITIAN}

1. Analisis Univariat

Tabel 1. Distribusi Karakteristik di TK Frater Bakti Luhur Makassar $(n=48)$

\begin{tabular}{|c|l|l|}
\hline Karakteristik & $\mathrm{n}$ & $\%$ \\
\hline Umur & & \\
4 tahun & 12 & 5,0 \\
5 tahun & 21 & 4,7 \\
6 tahun & 15 & 1,3 \\
\hline Jenis kelamin & & \\
Laki-laki & 25 & 2,1 \\
Perempuan & 23 & 7,9 \\
\hline
\end{tabular}


Berdasarkan tabel 1 menunjukkan bahwa dari 48 responden didapatkan bahwa karakteristik umur responden terbanyak yaitu 5 tahun sebanyak 21 responden $(34,7 \%)$. Karakteristik jenis kelamin responden terbanyak yaitu laki-laki sebanyak 25 responden $(52,1 \%)$.

2. Analisis Bivariat

Tabel 2. Hubungan Antara Bermain Mengenal Warna dengan Perkembangan Kognitif Anak di TK Frater Bakti Luhur Makassar

\begin{tabular}{|c|c|c|c|c|c|c|}
\hline \multirow{3}{*}{$\begin{array}{c}\text { Bermain } \\
\text { mengenal } \\
\text { warna }\end{array}$} & \multicolumn{4}{|c|}{$\begin{array}{c}\text { Perkembangan } \\
\text { Kognitif Anak }\end{array}$} & \multirow{2}{*}{\multicolumn{2}{|c|}{ Jumlah }} \\
\hline & \multicolumn{2}{|c|}{$\begin{array}{c}\text { Berkemb } \\
\text { ang }\end{array}$} & \multicolumn{2}{|c|}{\begin{tabular}{|c|} 
Tidak \\
berkemb \\
ang
\end{tabular}} & & \\
\hline & $\mathrm{n}$ & $\%$ & $\mathrm{n}$ & $\%$ & $\mathrm{n}$ & $\%$ \\
\hline Baik & 32 & 94,1 & 2 & 5,9 & 34 & 100,0 \\
\hline Kurang & 9 & 64,3 & 5 & 35,7 & 14 & 100,0 \\
\hline Jumlah & 41 & 85,4 & 7 & 14,6 & 48 & 100,0 \\
\hline \multicolumn{7}{|c|}{$p=0,017$} \\
\hline
\end{tabular}

Berdasarkan hasil uji statistik dengan Chi-square diperoleh nilai $p=0,017$. Karena nilai $p<\alpha=0,05$, maka hipotesis alternatif diterima dan hipotesis nol ditolak. Interpretasi ada hubungan antara bermain mengenal warna dengan perkembangan kognitif anak di TK Frater Bakti Luhur Makassar..

\section{PEMBAHASAN}

Berdasarkan penelitian yang diperoleh di TK Frater Bakti Luhur Kota Makassar hasil uji statistik dengan Chi-square yaitu $p=0,017$, artinya ada hubungan antara bermain mengenal warna dengan perkembangan kognitif anak di TK Frater Bakti Luhur Makassar, karena responden yang baik dalam bermain mengenal warna lebih cenderung mengalami perkembangan kognitif.

Hasil penelitian ini didapatkan responden yang baik dalam bermain mengenal warna tetapi tidak mengalami perkembangan kognitif, hal ini disebabkan karena anak belum dapat melompat dengan satu kaki tanpa berpegangan, belum dapat berpakaian sepenuhnya dan belum dapat menggambar sedikitnya tiga bagian tubuh. Dalam penelitian ini terdapat pula responden kurang baik dalam bermain mengenal warna tetapi mengalami perkembangan kognitif, hal ini disebabkan karena anak sudah dapat menyebutkan kembali warna benda yang ditanyakan oleh guru, menunjuk warna yang ditanyakan oleh guru dan mengancing bajunya.

Hasil penelitian ini sesuai dengan penelitian yang telah dilakukan oleh Ratnasari, dkk., (2017), ada hubungan bermain mengenal warna dengan perkembangan kognitif anak usia prasekola di TK Dharma Wanita Kelurahan Tlogomas Kecamatan Lowokwaru. Kemampuan mengenal warna termasuk dalam bidang pengembangan kemampuan visual, karena yang dikembangkan dalam pengembangan kognitif tersebut anak harus dapat mengetahui, mengenal, membandingkan, dan menjawab warna, ukuran, dan bentuk suatu benda. Permainan pengenalan warna dapat meningkatkan kemampuan kognitif anak, sehingga permainan ini dapat diterapkan pada anak usia prasekolah sebagai media pembelajaran.

Penelitian Hastuti (2015), mengemukakan bahwa ada hubungan antara variasi berman dengan pekembangan kognitif pada anak Usia Prasekolah kelompok A TK PGRI 01 Kedungkandang Malang. Dengan variasi bermain, anak mendapatkan banyak pengetahuan dan hal tersebut menjadi stimulasi dalam perkembangan kognitif anak. Semakin bervariasi rangsangan yang diterima, maka makin kompleks hubungan antar sel-sel otak. Semakin kompleks rangkaian hubungan antar sel-sel otak maka makin tinggi dan semakin kuat daya pikir (kognitif) anak. Bila dikembangkan terus-menerus, daya pikir (kognitif) anak akan semakin berkembang dan anak akan memiliki variasi kecerdasan (multiple intelegensi). Interaksi anak dan permainan merupakan sumber utama untuk berkembangnya motivasional, kognitif, dan afektif. Karena permainan pada masa kanakkanak mempunyai hubungan langsung dengan aspek-aspek tersebut. Oleh karena itu stimulasi dan interaksi serta variasi bermain dan kesempatan bermain dan kesempatan eksplorasi merupakan faktor penting bagi pertumbuhan anak.

Bermain merupakan suatu aktivitas di mana anak dapat melakukan atau mempraktikkan keterampilan, memberikan ekspresi terhadap pemikiran, menjadi kreatif, mempersiapkan diri untuk berperan dan berperilaku dewasa. Sebagai suatu aktivitas yang memberikan stimulasi dalam kemampuan keterampilan, kognitif, dan afektif maka sepatutnya diperlukan suatu bimbingan, mengingat bermain bagi anak merupakan suatu kebutuhan bagi dirinya sebagaimana kebutuhan lainnya seperti kebutuhan makan, kebutuhan rasa aman, kebutuhan kasih sayang, dan lain-lain (Hidayat, 2012).

Menurut Piaget dalam Dewi, dkk., (2015), menjelaskan perkembangan kognitif anak toddler berada pada tahap pra-operasional (27 tahun). Tahap ini ditandai oleh adanya 
pemakaian kata-kata lebih awal dan memanipulasi simbol-simbol yang menggambarkan objek atau benda dan hubungan diantara mereka. Tahap praoperasional juga ditandai oleh beberapa hal, antara lain: egosentrisme, ketidakmatangan pikiran tentang sebab-sebab dunia di fisik, kebingungan antara simbol dan objek yang mereka wakili, kemampuan untuk fokus pada satu dimensi pada satu waktu dan kebingungan tentang identitas responden dan objek.

Perkembangan kognitif dapat dirangsang melalui permainan. Hal ini dapat terlihat pada saat anak bermain, maka anak akan mencoba melakukan komunikasi dengan bahasa anak, mampu memahami obyek permainan seperti dunia tempat tinggal, mampu membedakan khayalan dan kenyataan, mampu belajar warna, memahami bentuk ukuran dan berbagai manfaat benda yang digunakan dalam permainan,sehingga fungsi bermain pada model demikian akan meningkatkan perkembangan kognitif selanjutnya (Hidayat, 2012).

Menurut asumsi peneliti, menunjukkan adanya konsistensi dengan teori yang ada, bahwa ada hubungan antara bermain mengenal warna dengan perkembangan kognitif anak. Bermain mengenal warna dapat menghasilkan pengertian atau memberikan informasi, memberikan kesenangan maupun membangakan imajinasi yang lebih mendominan pada belahan otak kiri anak usia dini. Bermain memberikan ransangan yang tepat bagi anak-anak, melalui bermain memungkinkan anak-anak mengembangkan kompetensi dan keterampilan yang diperlukannya dengan cara yang menyenangkan, dan bermain dapat melatih struktur-struktur kognitif anak. Faktor lain yang juga turut mempengaruhi perkembangan kognitif anak seperti bervariasinya permainan yang diberikan. Bervariasinya permainan yang diberikan pada anak mengakibatkan semakin bervariasinya rangsangan yang diterima anak, sehingga makin kompleks hubungan antar selsel otak.

\section{KESIMPULAN}

Ada hubungan antara bermain mengenal warna dengan perkembangan kognitif anak di TK Frater Bakti Luhur Makassar

\section{SARAN}

1. Diharapkan pihak sekolah dapat memberikan pola bermain yang bervariasi pada anak, karena permainan yang bervariasi akan memberikan kesempatan pada anak untuk mengeksplorasi kemampuannya yang merupakan faktor penting bagi pertumbuhan anak.

2. Diharapkan petugas kesehatan tenaga kesehatan lebih meningkatkan lagi pemantauan secara rutin deteksi dini terhadap penyimpangan perkembangan anak serta memberikan penyuluhan pada responden tua tentang cara menstimulasi perkembangan anak, untuk dapat diterapkan dalam kehidupan sehari-hari.

3. Diharapkan peneliti selanjutnya yang meneliti tentang faktor lain lain yang terkait dengan perkembangan kognitif anak dengan memperbanyak sampel penelitian untuk mengetahui tingkat penyebaran datanya sama atau tidak dengan penelitian sekarang.

\section{DAFTAR PUSTAKA}

Dewi, R. C., Oktiawati, A., \& Saputri, L. D. (2015). Teori \& Konsep Tumbuh Kembang Bayi, Toddler, Anak dan Usia Remaja. Yogyakarta: Nuha Medika.

Hastuti, A. P. (2015). Hubungan Antara Variasi Bermain dengan Perkembangan Kognitif pada Anak Usia Pra Sekolah Kelompok A di TK PGRI 01 Kedungkandang Malang. Jurnal Kesehatan Hesti Wira Sakti, Volume 3, Nomor 3, 4-14.

Hernia, H. (2013). Kemampuan Mengenal Warna pada Anak Usia 4-5 Tahun di TK Segugus III Kecamatan Panjatan Kabupaten Kulon Progo. Skripsi Fakultas IImu Pendidikan Universitas Negeri Yogyakarta.

Hidayat, A. A. (2012). Pengantar Ilmu Keperawatan Anak 1. Jakarta: Salemba Medika.

Kasmini, L., \& Purba, N. (2016). Pengaruh Eksperimen Sains pada Materi Mencampur Warna Terhadap Perkembangan Kognitif Anak Kelompok B2 pada TK Pertiwi Banda Aceh. ISSN 2355-102X, Volume III Nomor 1, 31-42.

Kemenkes RI. (2018). Hasil Utama Riskesdas 2018. Jakarta: Kementerian Kesehatan RI.

Khaironi, M. (2018). Perkembangan Anak Usia Dini. Jurnal Golden Age Hamzanwadi University, Vol. 3 No. 1, 112. 
Muliani, N. M., Gading, I. K., \& Mahadewi, L. P. (2017). Pengaruh Metode Discovery Terhadap Kemampuan Mengenal Warna pada Anak Taman Kanak-Kanak. e-Journal Pendidikan Anak Usia Dini Universitas Pendidikan Ganesha Jurusan Pendidikan Guru Pendidikan Anak Usia Dini (Volume 5. No. 1), 1-10.

Notoatmodjo, S. (2014). Metodologi Penelitian Kesehatan. Jakarta: PT. Rineka Cipta.

Ratnasari, R., Utami, N. W., \& Rosdiana, Y. (2017). Hubungan Bermain Mengenal Warna dengan Perkembangan Kognitif Anak Usia Prasekolah di TK Dharma Wanita Kelurahan Tlogomas Kecamatan Lowokwaru Kota Malang. Nursing News, Volume 2, Nomor 2, 490-502.

Vanagosi, K. D. (2015). Analisis Kinesiologi Teknik Cabang Olahraga Panahan. Jurnal Pendidikan Kesehatan Rekreasi, Volume 1 , 70-75.

WHO. (2018). Early Child Development. Fact Sheets of WHO. 